\title{
CARACTERIZAÇÃO AMBIENTAL DA BACIA HIDROGRÁFICA DO CORREGO DO JUCO EM CÁCERES, MT
}

\author{
Verônica Martinez de Oliveira Raymundi ${ }^{(a)}$, Sandra Baptista da Cunha ${ }^{(b)}$, Celia Alvez Souza \\ (c), Maxuel Ferreira Santana ${ }^{\text {(d) }}$ \\ (a, ce d) Departamento de Geografia/ Faculdade de Ciências Humanas, Universidade Estadual do Estado de Mato \\ Grosso - UNEMAT ${ }^{(\mathrm{A})}$ veronica.raymundi@ hotmail.com; ${ }^{(\mathrm{c})}$ celiaalves@ globo.com; ${ }^{(\mathrm{d})}$ maxfsantana@ $@$ hotmail.com) \\ ${ }^{(b)}$ Professorado Programa de pós graduação UFF (E-mail: sandracunha@ openlink.com.br)
}

\section{EIXO: BACIAS HIDROGRÁFICAS E RECURSOS HÍDRICOS: ANÁLISE, PLANEJAMENTO E GESTÃO}

\section{Resumo}

As bacias hidrográficas representam um conjunto de terras drenadas por um curso d'água e seus afluentes que interagem com os elementos ambientais que a compõem. Sendo assim esta pesquisa teve como objetivo fazer caracterização ambiental do córrego do Junco em Cáceres, MT, relacionado os elementos ambientais com a dinâmica que envolve a drenagem da bacia. $\mathrm{O}$ levantamento das informações foramrealizadas a partir de referenciais teóricos e pelo projeto RADAMBRASIL através de imagem de satélite LANDSAT 5 TM a partir do software Spring ${ }^{\circledR}$ 5.2.7 e layout pelo software ArcGis ${ }^{\circledR}$ 10.2. A área é composta por Depósitos Detríticos e Aluviões Atuais com formação da Depressão do Alto Paraguai e das Planícies e Pantanais Mato- grosensses, os solos predominantes são Argissolo Vermelho - Amarelo Distrófico e Gleissolo-Háplico Tb Eutrófico. O clima característico da área de estudo éoTropicalMegátermicoSubúmido.

Palavras -Chave:Condicionantes ambientais, bacias hidrográficas , mapa temático.

\section{1- Introdução}

As bacias hidrográficas formam redes que drenam a água por longos trechos e interagem diretamente com diversos elementos naturais presentes no espaço terrestre (CUNHA e GUERRA, 2012). Aspectos referentes à geologia, geomorfologia, relevo, tipo de solo e clima compreende um conjunto de fatores que ao se relacionarem reproduz uma dinâmica própria.

A união entre os diversos elementos da natureza e suas características são essenciais para entender o funcionamento e estrutura das bacias hidrográficas. Esses fatores estão presentes em todas as esferas do espaço terrestre, sua interação possibilita a formação da paisagem natural em diferentes escalas.

$\mathrm{Na}$ natureza cada elemento representado pela geologia, geomorfologia, relevo, solo, clima e vegetação apresenta uma importante característica, sedo fundamental sua compreensão ao analisar o comportamento natural de um espaço físico.

Neste contesto Ross (2011) afirma que ageomorfologiacompreende os estudos relacionados à forma do relevo, envolvendo as características de sua formação, sendo também uma estrutura que mantém relação com o ambiente natural. Ageologia explica a estrutura econstituição da Terra, por 
meio das forças internas e externas que agem sobre as rochas modelando o relevo, bem como sua composiçãoquímica(GUERRA e GUERRA).

O solo por sua vez esta associado à vegetação, ao fixar suas raízes esustentaras espécies da flora fornecendo a água e nutrientes (ARAUJO e HUNGRIA 1994).

O clima podeser definido como um conjunto de interações entre a atmosfera, oceanos, massas de ar, vegetação. O resultado dessa interação possibilita a definição climática de uma localidade (MAITELLI,2005).

A dinâmica de uma bacia hidrográfica está associada à atuação dos elementos naturais integrados a ela. Nesta perspectiva podemos destacar a bacia do córrego do Junco, que ao reunir as diversas características naturais, forma um importante elo de descarga hídrica com o rio Paraguai. Deste modo a grande bacia do rio Paraguai recebe além da água, sedimentos e compostos solúveis.

Os levantamentos das características ambientais do córrego do Junco produzirão informações sobre a sua estrutura e dinâmica de funcionamento da bacia. Sendo assim o presente estudo tem como objetivo fazer a caracterização ambiental do córrego do Junco, relacionados aos elementos geológicos, geomorfológico, climático, pedológico e os tipos de vegetação, para então relaciona-los com a dinâmica que envolve a drenagem da bacia.

\section{2 - MATERIAL E MÉTODO}

\section{1 -Área de estudo}




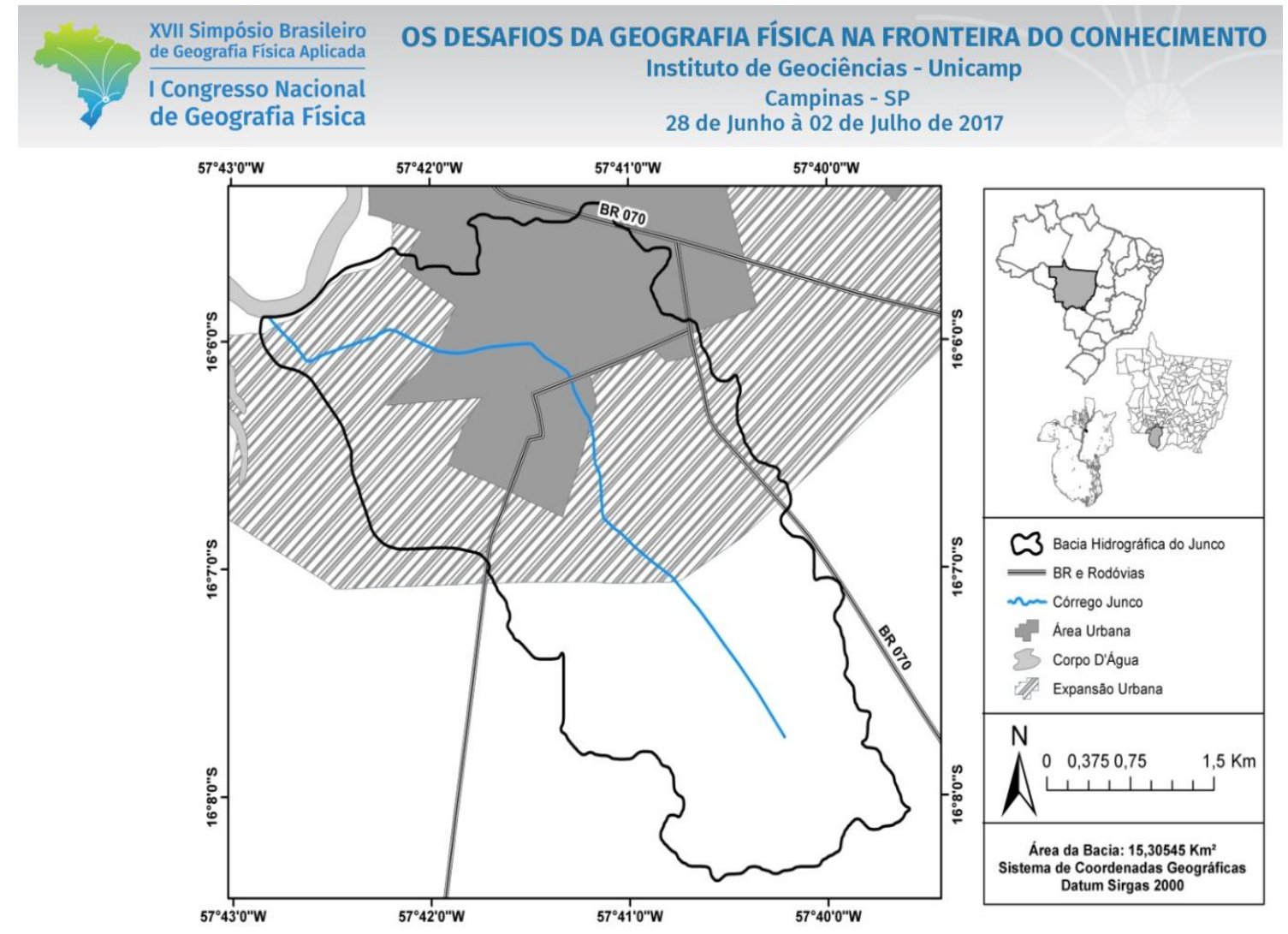

Figura 1. Localização da bacia hidrográfica do córrego Junco, município de Cáceres-MT.

Córrego do Junco ocupa uma área de 15,30545km,sendo afluente da margem esquerda do rio Paraguai(baía do Poção)está localizado do município de Cáceres - Sudoeste do Estado de Mato Grosso entre as coordenadas $16^{\circ} 05^{\prime} 0^{\prime \prime}$ a $16^{\circ} 09^{\prime} 0$ " de Latitude Sul e $57^{\circ} 43^{\prime} 0$ " a $57^{\circ} 39^{\prime} 0$ " de Longitude Oeste.

Maior parte da bacia abrange a área urbana da cidade de Cáceres, restando apenas uma pequena porção territorial localizada zona rural. O alto curso do córrego do Junco está localizado na Fazenda Rancho Verde e no bairro Santo Antonio, no médio curso o córrego percorre por um trecho do bairro do Junco até atingir o baixo curso passando pelo bairro Jardim das Oliveiras, conhecido popularmente como Empa.

\section{3 -Procedimentos metodológicos}

\section{1 -Levantamento das características ambientais da bacia}

Para obter informações sobre condicionantes geoambientais da bacia do córrego do junco, foram realizados levantamentosdeinformações (bibliografias, relatório, mapas)e observação direta no campo por meio de visitas in locopossibilitando a confirmação das informações documentais obtidas pelos mapas temáticos da área de estudo.

O levantamento das informações referente às condições geoambientais foram obtidas por dados secundários através dos relatórios do Projeto RADAMBRASIL (1982) e SEPLAN (2011)Posteriormente foram interpretados por meio de visualização de imagens obtidas de satélite 
LANDSAT 5 TM, segmentação e classificação das características geoambientais a partir do software Spring ${ }^{\circledR}$ 5.2.7 e layout pelo software ArcGis ${ }^{\circledR}$ 10.2.

\section{4 - RESULTADOS E DISCUSSÕES}

\section{1 - Clima}

A bacia esta localizada na unidade climática denominada de Clima Tropical MegátermicoSubúmido das Depressões e Pantanais de Mato Grosso de acordo com a classificação de Tarifa (2011).Em função das baixas altitudes (80 a 300 metros) estas áreas são fortemente aquecidas, ocorre o aumento da densidade do ar (maior pressão atmosférica), aumentando desta forma a capacidade de armazenamento da radiação solar (MAITELLI, 2005).

A distribuição da precipitação apresenta dois períodos bem definidos, isto é, época de chuvas intensas (novembro a marco) e período de estiagem (abril a outubro). O volume de precipitação atinge a variação varia de 1200 a $1400 \mathrm{~mm}$ no período chuvoso e no período de estiagem varia de 300 a 350 m (MAITELLI, 2005).

As temperaturas médias anuais variam de $25^{\circ}$ a $26^{\circ} \mathrm{C}$, enquanto as máximas oscilam entre $32^{\circ} \mathrm{C}$ e $33^{\circ} \mathrm{C}$ podendo chegar a valores que ultrapassam $35^{\circ} \mathrm{C}$ nos períodos mais quentes. As temperaturas mínimas indicam valores médios anuais de $21,7^{\circ} \mathrm{C}$ e $21,3^{\circ} \mathrm{C}$. Os tais valores (mínimos) são relativamente elevados, podendo haver no inverno austral (junho, julho e agosto) uma frequência esporádica, porém intensa de mínimas de 0 a $4^{\circ} \mathrm{C}$, decorrente das frentes anticiclonais polares (TARIFA, 2011).

\subsection{Geologia}

A bacia hidrográfica do córrego do Junco apresenta uma área geológica pouco diferenciada em suas formações, sendo caracterizada pelos depósitos Detríticos e Aluviões atuais (Figura 02). Tais estruturas compreendem um período de formação recente, pois datam do cenozóico (pleistoceno, holoceno). A áreada bacia é predominantemente ocupada pelos Depósitos Detríticos, sua extensão corresponde a14,827kmda Formação Pantanal, osAluviões Atuais ocupa uma área de 0, 488 km²no baixo curso, sendoinfluenciado pela dinâmica do rio Paraguai. 


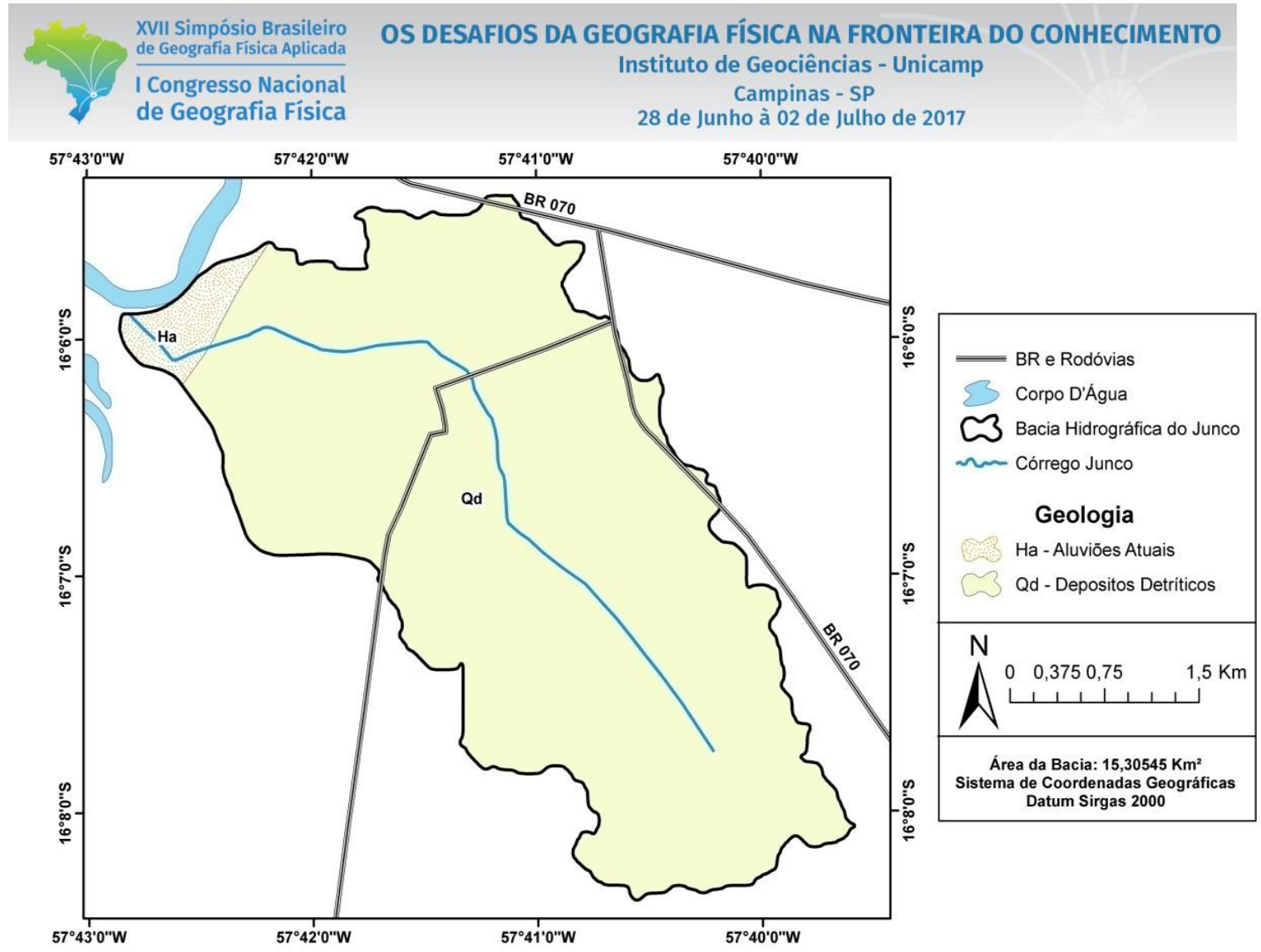

Figura 02 - Mapa Geológico da bacia do córrego Junco

De acordo com Corrêa e Couto (1972)a Formação Pantanal é constituída de uma sequência argilo-arenosa inconsolidada, estratificada horizontalmente, formada por uma alternância de argila cinza e areia média a fina, de cor branca, amarela e vermelha, com classificação regular a boa. Além do quartzo, as areias possuem conteúdo regular de caulim. Entremeados às camadas argilosas e arenosas, são localizados leitos laterizados de pequena espessura de areias e conglomerados finos.

Almeida (1964)diz que, os depósitos da Formação Pantanal são poucos espessos, com a composição areno-argilosos e síltico-argilosos, com granulometria predominantemente fina ou muito fina, ocorrendo também areias médias a conglomeráticos. Os grãos de quartzo são subarredondados e arredondados, as superfícies polidas com intercalações de níveis argilosos, tendo a fração cascalho, o resultado da movimentação ou dinâmica atual dos rios.

As coberturas detríticas presentes na bacia do córrego do Junco correspondem a sedimentos classificados como colúvios, colúvio - aluviais e alúviais. Os sedimentos classificados como colúvio aluviais são predominantes e sua abordagem é feita sem separação, por estarem quase sempre associadas e devido à dificuldade de separação na escala de mapeamento (BRASIL, 1982).

Os Aluviões Atuais encontram no baixo curso da bacia hidrográfica, sua origem está relacionada à dinâmica de cheia do rio Paraguai, quando transbordam águas e sedimentos, depositando-os na planície de inundação. Nesse processo, misturam-se aos materiais transportados pelo córrego Junco. 
Para Barros et al. (1982),o processo de deposição sedimentar pode ocorrer através dos depósitos de canal, barra, em pontal e transbordamento. A variação na composição do material depositado pode ser de areias, silte, argila e cascalho, reconhecendo-se que as camadas depositadas possuem pequena espessura, não atingindo 10 metros.

De acordo com Santos (2013) os aluviões constituem como sendomateriaisincosolidados, alojados em planície fluviais e terraços, podendo apresentar variações nos sedimentos depositado sendoconstituídos de areia, silte, argila e cascalho, apresentando pequena camada comespessura que atinge menos 10 metros.

\section{3 -Geomorfologia}

A bacia hidrográfica do córrego Junco possui duas unidades de relevo: Depressão do Rio Paraguai e a Planície e Pantanais e Pantanais Mato-GrossensesRio Paraguai. (Figura 03)

A unidade geomorfológica caracterizada pela Depressão do Rio Paraguai ocupa uma área de 14, 703km²na bacia do córrego do Junco, abrangendo extensas áreas rebaixadas da bacia. A depressão apresenta umpequeno caimento topográfico, com altimetria que oscila entre 142 a 119 metros de altitude. Segundo o RADAMBRASIL (1982), a Depressão do Alto Paraguai corta litologias do précambriano, que se encontram parcialmente encobertas por sedimentos quaternários da Formação Pantanal. 


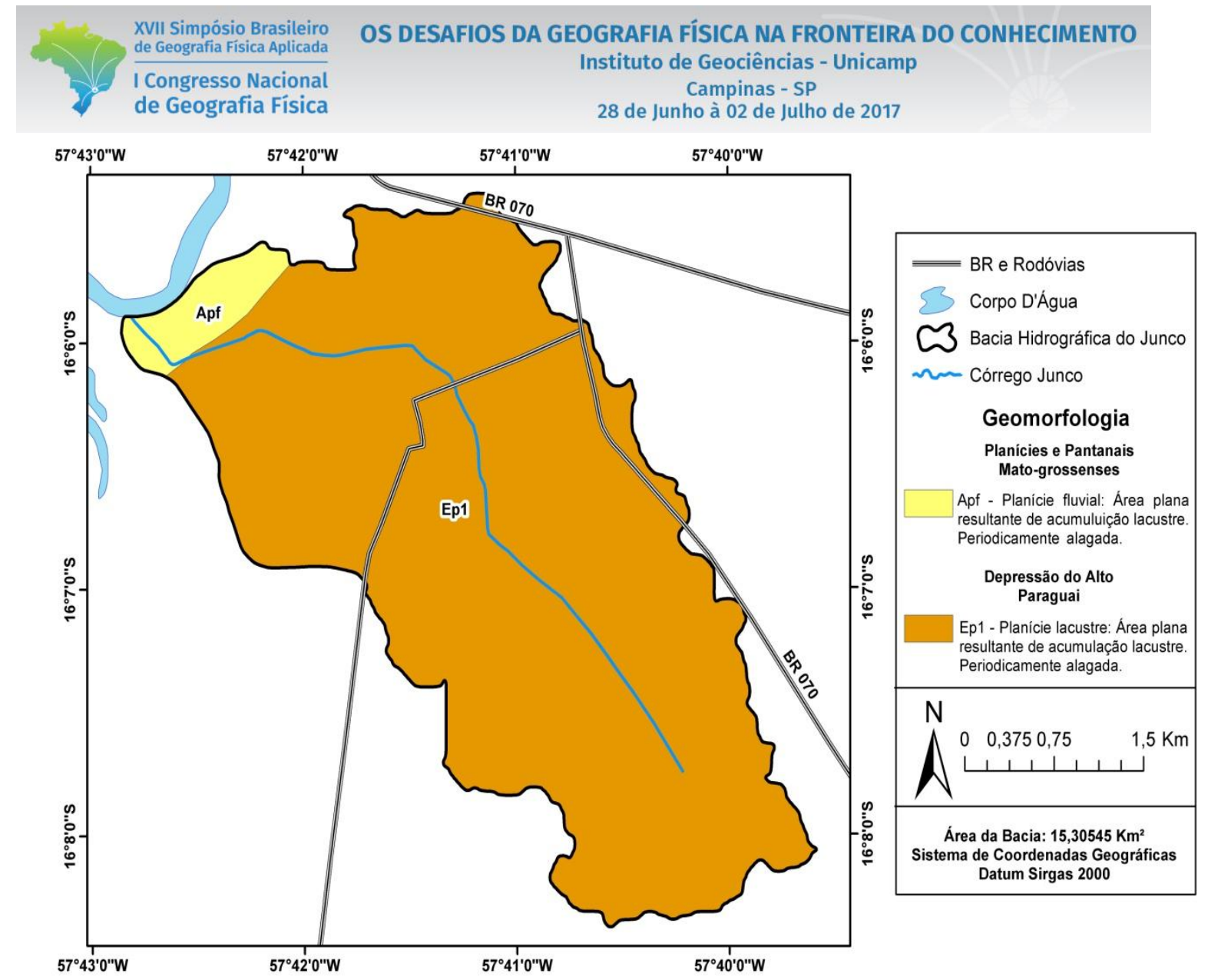

Figura 03- Mapa Geomorfológico da bacia do córrego.Elaborado por RAYMUNDI (2017) a partir dos dados presentes no RADAMBRASIL (1982).

Sobre estas condições topográficasa142 m de altitude, encontra-se a nascente do córrego do Junco, formando um curso drenado por um modesto caimento direcionado até a confluência com a baía do Poção localizada no rio Paraguai.

As Planícies e Pantanais Mato-grossensesencontra-seno baixo curso da bacia do córrego do Junco próximo à confluência com rio Paraguai. A morfologia da planície de inundação é representada por uma área plana e com baixa declividade sujeita as inundações durante os períodosde cheia do rio Paraguai.

\section{4 -Solos}

$\mathrm{Na}$ bacia hidrográfica registra a ocorrência de dois tipos de solos, sendo o Argissolo Vermelho-Amarelo Distrófico e o GleissoloHáplicoEutrófico.(Figura 04).

\subsection{1 - Argissolo Vermelho-Amarelo Distrófico}

O Argissolo Vermelho - Amarelo Distrófico, apresenta - se com maior expressividade na bacia do córrego do Junco, com umaárea corresponde a14,655 km².Conforme Oliveira et al. (1982), o 
solo Argissolo Vermelho-Amarelo Distrófico possui horizonte A moderado, sobrejacente ao Horizonte $\mathrm{Bt}$, com estrutura fraca a moderada em blocos subangulares com serosidade comum, moderada ou forte. Na maioria, e, sobretudo, naqueles desenvolvidos a partir de sedimentos do Quaternário, a serosidade é ausente, sendo então caracterizados pela alta relação textural, seguida da relação silte/argila e baixo grau de floculação.

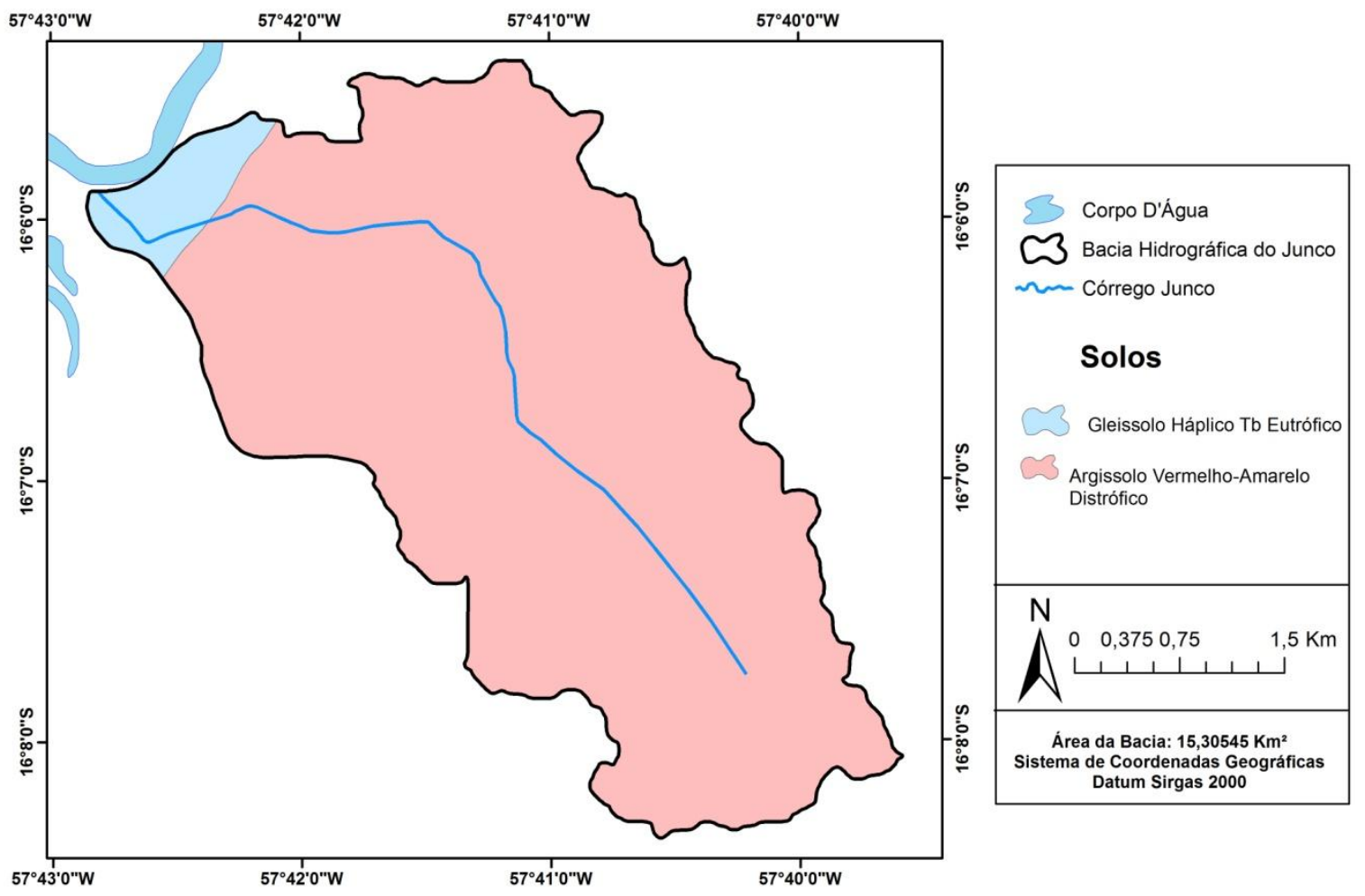

Figura 04- Mapa de solos da bacia hidrográfica do córrego do Junco. Elaborado por RAYMUNDI (2017) a partir dos dados presentes no RADAMBRASIL (1982).

\subsection{2 -GleissoloHáplico Tb Eutrófico}

O GleissoloHáplico Tb Eutrófico encontra-se no baixo curso da bacia, recebendo influênciado rio Paraguai. Esse tipo de solo é caracterizado por apresentar forte gleização em virtude do regime de umidade redutor que se forma nos meios anaeróbicos originados de encharcamentos periódicos ou constantes. Apresenta sequência de horizontes do tipo A, $\mathrm{Cg}$, com ou sem descontinuidade litológica, sendo o horizonte A do tipo moderado. A sua ocorrência se limita às áreas deprimidas sujeitas às inundações e às margens de curso de água, relacionados aos sedimentos recentes do período Quaternário (OLIVEIRA et al., 1982). 
Para Oliveira et al. (1982), o GleissoloHáplico Tb Eutrófico é um solo profundo, mal drenado, de baixa permeabilidade com características físicas e químicas muito variadas, especialmente devido à natureza do material de origem, como também à distância do regime hídrico destas áreas.

\section{5 - CONSIDERAÇÕES FINAIS}

A bacia hidrográfica do córrego do Junco, representada por um único córrego perene (córrego do Junco), constitui uma importante fonte de água, que diferente dos demais córregos, se origina nas áreas rebaixadas da Depressão do Alto Paraguai, e atinge rio Paraguai, tornando-se um contribuinte desta bacia. Deste modo, é possível destacar algumas, características que envolvem os elementos ambientais presente na bacia.

O clima Tropical MegátermicoSubúmido das Depressões e Pantanais de Mato Grosso, corresponde ao tipo climático encontrado na área de estudo. O relevo é considerado um fator de forte influência neste tipo climático,

A composição geológica agrupa duas formações, sendo os Depósitos Detríticos e Aluviões Atuais. Os Depósitos Detríticos ocupam extensa área da bacia do Junco, restando uma pequena porção representada pelos Aluviões Atuais. Ambas as formações são recentes (pleistoceno, holoceno), e apresentam como característica uma intensa sedimentação, relacionada à abertura da depressão do rio Paraguai, período este marcado por grandes oscilações climáticas.

A Depressão do rio Paraguai, agrupa uma unidade de relevo pouco dissecado, apresentando um leve caimento topográfico. Nesta formação geomorfológica o córrego do Junco nasce e percorre por um longo trecho de pequena declividade, até atingir as Planícies e Pantanais Mato grosensses.

Os tipos de solos que predominam na área da bacia são o Argissolo Vermelho - Amarelo Distrófico. Estes solos são Pobres e formados por um horizonte Bt. OGleissoloHáplico Tb Eutrofico, encontra-se no baixo curso, sendo comuma esse solo encontrar-se em relevo plano, sujeito a inundação.

\section{Bibliografia}

ALMEIDA, F. F. M. Geologia do Centro-oeste Matogrossense. Boletim da Divisão de Geologia e Mineralogia. Rio de Janeiro, 1964. p.1-133.

ARAUJO, S. R.; HUNGRIA, M. Empresa brasileira de pesquisa agropecuária. Centro nacional de pesquisa de arroz e feijão: Centro nacional de pesquisa de soja - Brasilia:EMBRAPA- SPI 236 p.1994.

BARROS, A. M.; SILVA, R. H.; CARDOSO, O. R. F. A.; FREIRE, F. A.; SOUZA JUNIOR, J. J.; RIVETTI, M.; LUZ, D. S.; PALMEIRA, R. C. B.; TASSINARI, C. C. G. Geologia. In: BRASIL. Ministério das Minas e Energia. Secretaria Geral. Projeto RADAMBRASIL. Folha SD. 21 - Cuiabá; Geologia, Geomorfologia, Pedologia, Vegetação e Uso potencial da terra. Rio de Janeiro, 1982. p. 25 - 192.

Ministério das Minas e Energia. Secretaria Geral. Projeto RADAMBRASIL. Folha SD. 21 - Cuiabá; Geologia, Geomorfologia, Pedologia, Vegetação e Uso potencial da terra. Rio de Janeiro, 1982. p. 25 - 192. 
BRASIL. Ministério das Minas e Energia. Projeto RADAMBRASIL. Folha SE. 21 -Corumbá e parte da Folha SE.20: Geologia, Geomorfologia, Pedologia, Vegetação e Uso potencial da terra. Rio de Janeiro, 1982. $452 \mathrm{p}$.

CORREA, J. A.; COUTO, E. A. Projeto aluviões diamantíferos de Mato Grosso. 2 vol. Relatório Final. Goiânia: DNPM/CPRM, 1972.

CUNHA, S. B.; GUERRA, A.J. T.Degradação ambiental. In: GUERRA, A.J. T e CUNHA, S. B. (orgs.). $11^{\mathrm{a}}$ ed. Geomorfologia e meio ambiente. Rio de Janeiro: Bertrand Brasil, 2012.394p.;

EMBRAPA. Centro Nacional de Pesquisas de Solo (Rio de Janeiro, RJ). Sistema brasileiro de classificação de solo. - Brasília: Embrapa Produção de Informação; Rio de Janeiro: Embrapa solos p412, 1999.

GUERRA, A. T.; GUERRA, A. J. T. Novo dicionário geológico-geomorfológico. 6 ed. Rio de Janeiro: Bertrand Brasil, 2008.

LOUREIRO, R.L.; LIMA, J.P.S.; FONSAR, B. C. Vegetação: As regiões fitoecológicas, sua natureza e seus recursos econômicos In. BRASIL. Ministério das Minas e Energia. Projeto RADAMBRASIL. Folha SE. 21 Corumbá e parte da Folha SE.20: Geologia, Geomorfologia, Pedologia, Vegetação e Uso potencial da terra. Rio de Janeiro, 1982 p. 329-372.

MAITELLI, G.T. Interações atmosfera superfície. In: MORENO, Gislaine e HIGA, Tereza C. S. (orgs). Geografia de Mato Grosso: território, sociedade e ambiente.1 ed. Cuiabá: estrelinhas, p 238 a 249 2005.;

NUCCI, J. C; CAVALHEIRO, F. Cobertura vegetal em áreas urbanas - conceito e método. Geousp, São Paulo, n. 6, p. 29-36, 1999.

OLIVEIRA, V. A.; AMARAL FILHO, Z. P.; VIEIRA, P. C. Pedologia: levantamento exploratório de solos. In: BRASIL. Ministério das Minas e Energia. Secretaria Geral. Projeto RADAMBRASIL. Folha SD. 21 Cuiabá: Geologia, Geomorfologia, Pedologia, Vegetação e Uso potencial da terra. Rio de Janeiro, 1982. p. 257 400 .

ORIOLI, A.L.; FILHO, Z.P.A. ; OLIVEIRA, A.B. Pedologia: Levantamento Exploratório de Solos In. BRASIL. Ministério das Minas e Energia. Projeto RADAMBRASIL. Folha SE. 21 - Corumbá e parte da Folha SE.20: Geologia, Geomorfologia, Pedologia, Vegetação e Uso potencial da terra. Rio de Janeiro, 1982 p. 225-328.

RIBEIRO, J.F.; FONSECA, C.E.L. ; SILVA, J.C.S. Cerrado: Caracterização e recuperação de mata de galeria. Planaltina: Embrapa Cerrados, 2001 899p.

ROSS, J. L. S. Geografia do Brasil. Ed. Didática, São Paulo, 2011

ROSS, J. L. S.; SANTOS, L. M. Geomorfologia. In: BRASIL. Ministério das Minas e Energia. Secretaria Geral. Projeto RADAMBRASIL. Folha SD. 21 - Cuiabá: Geologia, Geomorfologia, Pedologia, Vegetação e Uso potencial da terra. Rio de Janeiro, 1982. p. 193 - 256.

SANO, S.M. e ALMEIDA, S.P. ed. Cerrado: ambiente e flora. Planaltina: EMBRAPA-CPAC, 1998 556p.

SANTANA, M. F .; SOUZA, C.A. Comportamentos geomorfológicos e sua influencia na morfologia fluvial do rio Paraguai no segmento entre a volta do Angical a foz do rio Sepotuba. ENCICLOPÉDIA BIOSFERA, Centro Científico Conhecer - Goiânia, v.11 n.21; p. 3035 2015;

SANTOS, M.S. Uso, ocupação da terra e dinâmica fluvial da bacia hidrográfica do córrego Cachoeirinha no município de Cáceres - Mato Grosso. Dissertação (Mestrado) - Universidade do Estado de Mato Grosso. Programa de Pós-Graduação em Ciências Ambientais, Cáceres/MT: UNEMAT, 2013 148f

SCHWENK, L. M. Domínios Biogeográficos. In: MORENO, Gislaine e HIGA, Tereza C. S. (orgs). Geografia de Mato Grosso: território, sociedade e ambiente.1 ed. Cuiabá: estrelinhas, p. 250 a 271 2005.;

SEPLAN. Atlas de Mato Grosso: abordagem socioeconômico-ecológica. Cuiabá - MT: Entrelinhas, 2011.96 p.

SOUZA, C. A.; LANI, J. L.; SOUSA, J.L. Origem e evolução do Pantanal Mato-grossense. VI Simpósio nacional de geomorfologia / regionalconferenceongeomorpholoy. Geomorfologia tropical e subtropical: processos, métodos e técnicas/ Tropical and subtropical geomorpholog: processesmethodsandtechniques. Goiânia 6 a 10 de setembro de 2006/ Brazil, Goiânia-GO, 6-10, 2006

SUGUIO, K. Geologia do quaternário e mudanças ambientais. São Paulo: Oficina de textos, 2010. 408 p.

TARIFA, J. R. Clima: análise e representação cartográfica. In: Mato Grosso - Secretaria de Estado de Planejamento e Coordenação Geral. Recursos naturais e estudos ambientais. Cuiabá-MT, 2011. 102p. 